\title{
Analysis of chip formation and cutting forces in end milling AISI D2 tool steel with different cutting tool geometries
}

\author{
Irina Beșliu*, Dumitru Amarandei and Delia Cerlincă \\ University "Ştefan cel Mare" from Suceava, Department of Mechanics and Technology, 720229 \\ Universităţii Street 13, Romania
}

\begin{abstract}
The purpose of this study was to investigate and establish the correlations between milling tool geometry ,cutting conditions, as input factors and the cutting forces variations and chips formation, as output factors when end milling of AISI D2 tool steel. The experiments were carried out using a Taguchi design array. The chip shape and microstructure and cutting force components were analyzed. The results of the study show that the cutting tool geometry has a great influence over segmented chip formation mechanism and cutting force levels.
\end{abstract}

\section{Introduction}

The cost- efficient machining processes that can be applied for hardened steel materials are of great interest now a days because of the high demand for this materials in industries as tooling, automotive and aircraft. Hardened steels parts exhibit better strength, thermal stability and wear resistance. The hard machining is defined as the process of machining materials with hardness higher than 45HRC. These machining techniques could be developed as a result of the advances in tool material technologies and in the machine tools components field that allowed higher material removal rates. Because of its ability of generating complex forms hard milling is usually used as a viable machining technique for machining different machine parts with free form surfaces.

Machining of hardened tool steels is considered a difficult process due to the high strength of the material. The thermo-mechanical phenomena of material removal in hard machining processes is difficult to anticipate and control, not only because of the machined material hardness that influence chip segmentation, but also because of the small uncut chips thickness involved and the higher machining speed that are usually used. Cutting forces magnitude plays an important role in material deformation and chip formation during machining. The study of the metal cutting forces generated during hard machining is of great interest because it's a barometer for material deformation, superficial layer internal stress and surface integrity estimation. Materials do not expose the same behavior when machined under the same cutting conditions. Even if ductile deformation absorbs large amounts of energy in comparison with a brittle case because the area under stress strain

\footnotetext{
*Corresponding author: irina.besliu@usv.ro
} 
curve is larger, when machining hard materials, ductile deformations are intended rather than brittle fracture. The main reason related to the aim of obtaining higher quality surface finish. Therefore, adequate cutting conditions and tool geometries must be used as to achieve high performance during machining of brittle and hard materials.

The formation of saw- chips is considered one of the primary characteristics in machining of hardened materials with geometrical defined cutting tools [2]. During hard machining, catastrophic failure in the primarily shear zone can be a cause either of the reach of thermoplastic instability or of cyclic crack initiation and propagation. There are researches [3] that had implied that the saw chip formation can be a result of the blocks movement which leave gradually because of a simultaneous slip along completely dislocated surface of with dimensions the free face and the face of tool associated with an extension with the bands of shearing concentrated, in the zone of microscopic cracks.

There are few researches that focus on the chip morphology and chip formation during hard machining of AISI D2 tool steel and most of them investigate the hard turning process.

Anthony [4] carried out an investigation on hard turning of AISI D2 steel using 3 types of cutting inserts and different machining conditions. He revealed that when the cutting speed is increased, magnitude of chip segments decreases.

Ben Salem and al. [3] had investigated the cutting force and chip morphology obtained during hard turning of AISI D2 material samples with 62HRC material hardness. Observations of the microstructure showed that chip formation has a continuous form (shearing) in case of annealing and it occurs by crack propagation in case of quenched structure. They also concluded that as the cutting speed increases, the chips become relatively ductile and chips segmentation also increases.

Gaitonde et al. [5] had investigated the influence of cutting speed, feed rate and radial depth of cut on maximum temperature, surface roughness and cutting force during milling of AISI D2 steel with TiAlN coated tungsten carbide insert and showed that a combination of low cutting speed, feed rate and depth of cut is essential to minimize the cutting force. M. Takacs and B. Z. Farkas [6] had investigated the effect of cutting parameters on surface roughness and cutting force components during hard turninig of AISI D2 tool cold steel with a hardness of $62 \mathrm{HRC}$. They concluded that the passive force is the most dominant force component.

Beşliu et al. [1] had investigated the deformation of chips generated in high speed face milling of tool steel X210Cr12 (AISI D2). The research was designed and developed in order to highlight the influence exerted by the workpiece material hardness HRC and cutting parameters on the apparent density $\rho_{p}$ of the chips.

The present paper, presents researches on cutting forces and chip formation mechanism in end milling processes of cold work tool steel AISI D2 with three different cutting tool geometries and under different machining conditions.

\section{Experimental setup}

Three types of end mills were considered: flat end mill, round corner end mill and ball end mill. The tools were coated carbide grade with thick PVD coating, produced by Kennametal, Grade KCPM15and KC633M with 4 flutes and $30^{\circ}$ flute helix, DIN 6527. The tools are coated carbide grade with a PVD multilayer coating (TiAlN, TiN, TiAlN). The tools diameters was of $\mathrm{d}=10 \mathrm{~mm}$.Cutting tests were carried out on a stiff vertical CNC machining center DOOSAN DT 360D. End milling tests are carried out on samples with dimensions of $200 \mathrm{~mm}$ long, $31 \mathrm{~mm}$ wide, $38 \mathrm{~mm}$ thick. For the experiments carried out according to Taguchi L9 orthogonal array, the levels of the input parameters are given in Table 1. Three levels were set between 0.08 to $0.2 \mathrm{~mm} / \mathrm{rev}$ for the feed rate parameter, and 
3200 and $4000 \mathrm{rev} / \mathrm{min}$ for the spindle speed parameter. Constant values were set for the axial depth of cut and radial depth of cut used in the experiments of ae $=2 \mathrm{~mm}$ and $a p=5 \mathrm{~mm}$. Three levels were also set in order to characterize the tool type influence over the considered output parameter. After analyzing the three cutting tool geometry chosen in the experiments, we concluded that the numerical parameter that differences them is the corner radius. In a way the ball end mills are in fact radius end mills with the radius equal with the radius of the end mill. The equipment employed for cutting forces measurements was a Kistler 9275 dynamometer Data processing of the three force components is carried out by means of DynoWave specialized software. Chip's shapes and roots were observed on a Scanning Electron Microscop (SEM) model Tescan Vega 3 and afterwards analyzed with specialized software MountainsMap Premium.

Table 1. The orthogonal array L9 and cutting forces measurements.

\begin{tabular}{|l|l|l|l|l|l|l|l|}
\hline $\begin{array}{l}\text { Exp. } \\
\text { run }\end{array}$ & \multicolumn{1}{|c|}{$\begin{array}{c}\text { Tool type } \\
\text { (corner radius) }\end{array}$} & $\begin{array}{c}\text { Spindle } \\
\text { speed } \\
\mathrm{n} \\
{[\mathrm{rev} /} \\
\mathrm{min}]\end{array}$ & $\begin{array}{c}\text { Cutting } \\
\text { speed } \\
\mathrm{s}[\mathrm{mm} / \\
\mathrm{min}]\end{array}$ & $\begin{array}{c}\text { Feed } \\
\text { rate } \\
\mathrm{f}[\mathrm{mm} / / \\
\mathrm{rev}]\end{array}$ & $\begin{array}{c}\text { Fx max } \\
{[\mathrm{N}]}\end{array}$ & $\begin{array}{c}\text { Fy max } \\
{[\mathrm{N}]}\end{array}$ & $\begin{array}{c}\text { Fz max } \\
{[\mathrm{N}]}\end{array}$ \\
\hline 1. & Flat end mill $(\mathrm{r}=0)$ & 3200 & 100.53 & 0.08 & 115.78 & 270.08 & 22.03 \\
\hline 2. & Flat end mill(r=0) & 3500 & 109.95 & 0.15 & 121.89 & 314.15 & 23.19 \\
\hline 3. & Flat end mill(r=0) & 4000 & 125.66 & 0.20 & 130.37 & 346.98 & 31.62 \\
\hline 4. & Radius end mill $(\mathrm{r}=2 \mathrm{~mm})$ & 3200 & 100.53 & 0.15 & 178.53 & 339.84 & 60.12 \\
\hline 5. & Radius end mill $(\mathrm{r}=2 \mathrm{~mm})$ & 3500 & 109.95 & 0.20 & 211.24 & 396.79 & 59.69 \\
\hline 6. & Radius end mill $(\mathrm{r}=2 \mathrm{~mm})$ & 4000 & 125.66 & 0.08 & 123.72 & 286.68 & 55.36 \\
\hline 7. & Ball end mill( $(\mathrm{r}=5 \mathrm{~mm})$ & 3200 & 100.53 & 0.20 & 362.43 & 683.53 & 187.26 \\
\hline 8. & Ball end mill(r=5 mm) & 3500 & 109.95 & 0.08 & 297.97 & 416.02 & 115.91 \\
\hline 9. & Ball end mill( $(\mathrm{r}=5 \mathrm{~mm})$ & 4000 & 125.66 & 0.15 & 299.75 & 460.63 & 136.35 \\
\hline
\end{tabular}

\section{Results and discussions}

Table 1 presents the measured values obtained for the three cutting force components: normal cutting force Fx, tangential cutting force Fy and axial cutting force Fz .

The experimental data was processed with MINITAB software. The regression equations obtained for the three cutting force components were not concluding. In Figure 1 the main effects plots for means are presented. As it can be seen the input parameters exert similar influences on each cutting force components. The tool corner radius seems to have an exponential effect over the cutting force components. Choosing tools with high corner radius will generate increase levels for the normal cutting force Fx, Tangential force Fy and axial cutting force $\mathrm{Fz}$.

The increase of spindle speed will result in slightly lower levels for the cutting force components. According to mean effect plots for means, the feed rate has a more pronounced influence over the tangential cutting force components. Chip formation mechanism was investigated considering the obtained SEM images of the chip root fracture and chip segmentation. It could be observed that the chips obtained have primarily and secondary serrated teeth. The secondary serrated teeth were formed al the free edge of the chip opposite the cutting edge point. The primary saw teeth are a result of the alternative phase compression and adiabatic shear process that results in force fluctuation. Secondary serrated teeth are formed by grouping primary serrated teeth at the free edge of the chip, opposite the cutting edge point. They are formed at almost equal pacing and as it can be seen the frequency of their formation increases with cutting speed (Figure 2). 

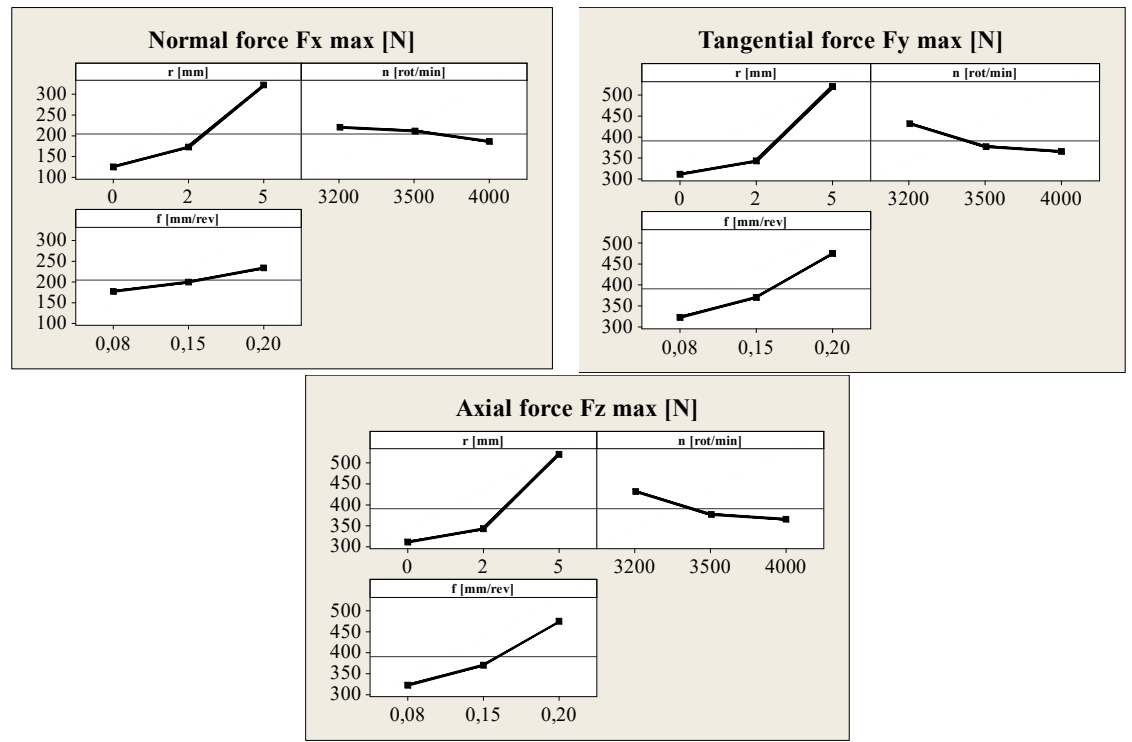

Fig. 1. Main effect plots for means.

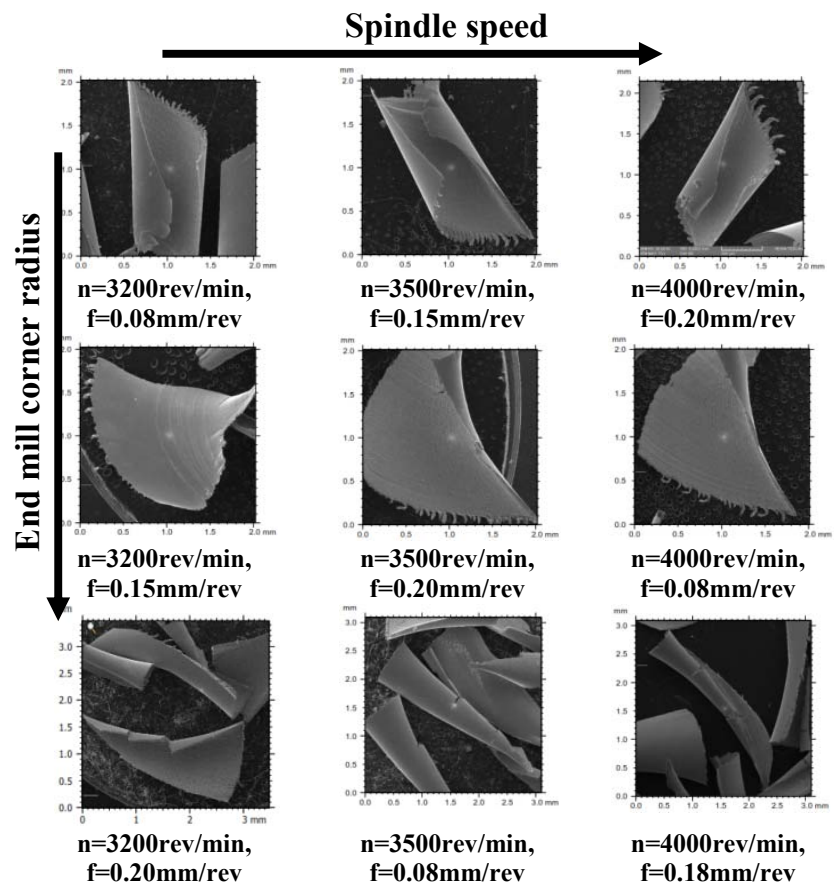

Fig. 2. Chips samples obtained in the experiments.

The cause of secondary serrated chip formation we believe to be the fan effect resulting from the way in which the unwanted material is detached by the helical cutting edges along a trochoidal trajectory, with a particular speed resulting chips in shape of spiral segments or needles. Therefore, the frequency of the secondary serration of the chips obtained by end milling processes has to be a function of depth of cut, helical angle of the cutting edge, end mill radius, cutting speed, feed rate and machined material proprieties. For the machining conditions chosen in this study, in the case of the milling tests carried out with flat end mill 
tool geometry the cutting processes were realized by ductile fracture. Brittle material failure was achieved when machining with radius end mills with spindle speed of 3200 rev/min and a feed rate of $0.15 \mathrm{~mm} / \mathrm{rev}$. Thus, we can conclude that lower cutting speed will generate brittle material fractures when milling with radius end mills. Ductile cutting was also achieved in the case of milling with ball end mills and a spindle speed of $3500 \mathrm{rev} / \mathrm{min}$ and a feed rate of $0.08 \mathrm{~mm} / \mathrm{rev}$. When milling with a ball end mill, a spindle speed of 4000 rev/min and a feed rate of $0.15 \mathrm{~mm} / \mathrm{rev}$ a ductile to brittle transition fraction was observed. When milling with a ball end mill, a spindle speed of $3200 \mathrm{rev} / \mathrm{min}$ and a feed rate of $0.20 \mathrm{~mm} / \mathrm{rev}$ brittle tearing marks could be observed. Therefore, when using ball end mill, in order to assure ductile fracture of the chips, lower feed rate levels must be chosen. The white layer is formed as a result of microstructural change in the martensitic structure and it indicates severe thermal damage due the presence of concentrated mechanical and thermal energies localized in this zones. White layer could be observed in SEM images obtained for the chips generated during machining with flat end mill and lowest levels for the spindle speed and feed rate and milling with radius end mill, a spindle speed of $n=3500$ $\mathrm{rev} / \mathrm{min}$ and a cutting feed of $\mathrm{f}=0.20 \mathrm{~mm} / \mathrm{rev}$.

Examination of the free surface of the chips obtained during experiments revealed regular (tests performed with ball end mills) and irregular arranged lamellar structures. Shear bands are more visible on the chips resulted from milling with ball end mills. Extreme temperatures are generated during plastic deformation of the chips. Without the presence of any coolant, thermal cracks form on chip surfaces. Adhered particles results from detachment of secondary serrated teeth.

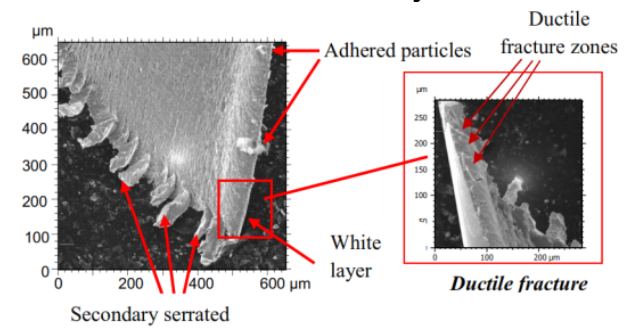

a. Flat end mill, $\mathrm{n}=3200 \mathrm{rev} / \mathrm{min}, \mathrm{f}=0.08 \mathrm{~mm} / \mathrm{rev}$
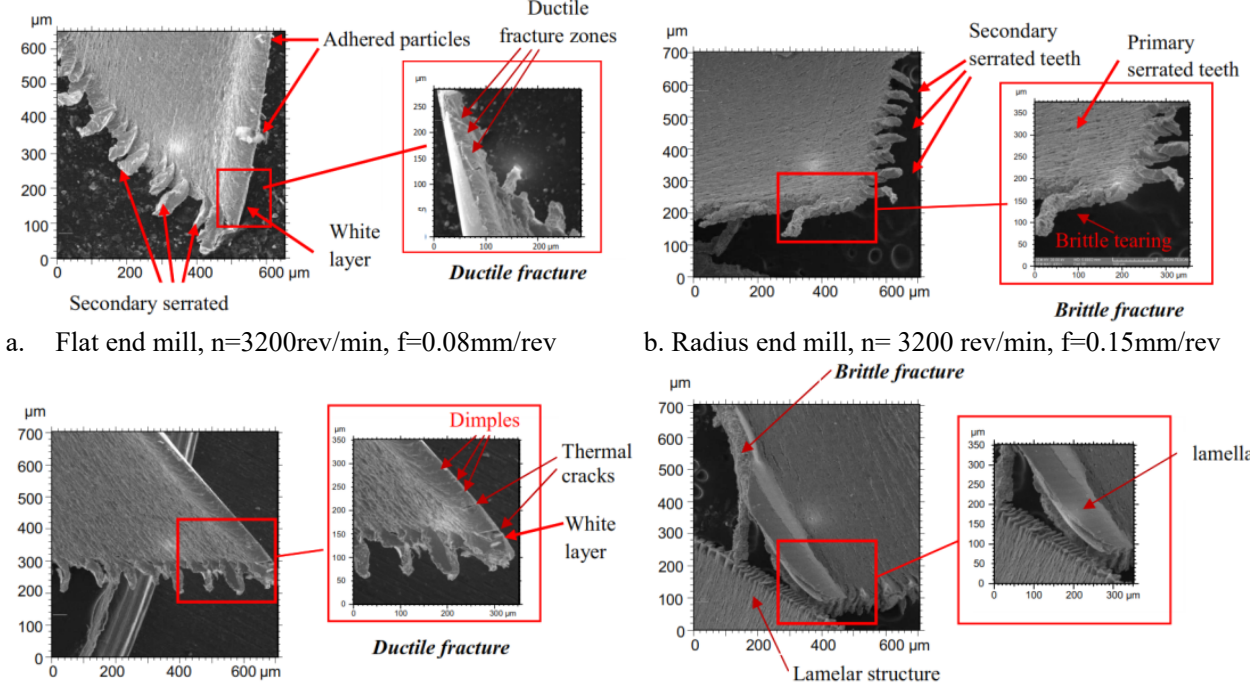

c. Radius end mill, $\mathrm{n}=3500 \mathrm{rev} / \mathrm{min}, \mathrm{f}=0.20 \mathrm{~mm} / \mathrm{rev}$

b. Radius end mill, $\mathrm{n}=3200 \mathrm{rev} / \mathrm{min}, \mathrm{f}=0.15 \mathrm{~mm} / \mathrm{rev}$

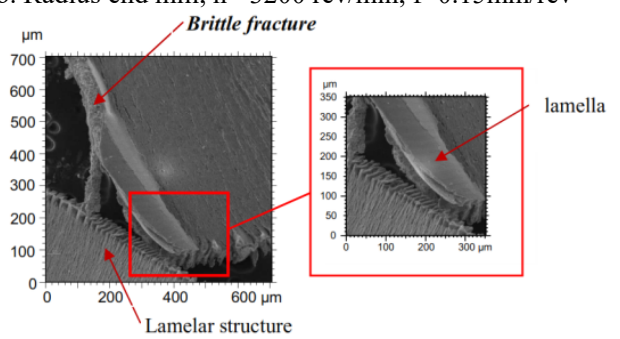

d. Ball end mill, $\mathrm{n}=3200 \mathrm{rev} / \mathrm{min}, \mathrm{f}=0.20 \mathrm{~mm} / \mathrm{rev}$

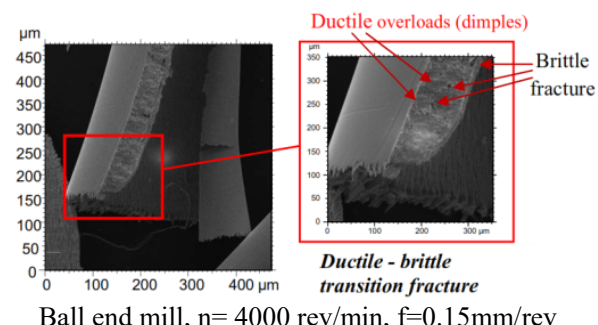

e. Ball end mill, $\mathrm{n}=4000 \mathrm{rev} / \mathrm{min}, \mathrm{f}=0.15 \mathrm{~mm} / \mathrm{rev}$

Fig. 3. Microscopic SEM images of chip morphology after end milling hardened AISI D2. 


\section{Conclusions}

This paper offers some information about the cutting force components and chip formation mechanism variation with the cutting parameters and end mill geometry that can and facilitates the choice of the cutting conditions in case of machining of the hardened AISI D2 tool steel.

Cutting force components were measured and analysed. There is a strong relation between normal cutting force, tangential cutting force and axial cutting force levels and the corner radius of the end mill tool. Even if milling with rounded end mills can assure improved surface finish, it will also result in higher cutting forces. The cutting force needed for machining will decreased when machining is carried out with higher cutting speeds. Increase in the feed rate increases the cutting force.

The cutting tool geometry and cutting parameters strongly influence the chip's shape and formation mechanism in end milling processes. Observations of the chips microstructures revealed that the process of the chip formation when milling hardened AISI D2 tool cold work steel can be perform throw brittle, ductile or ductile- brittle transition material fracture. For the parameters levels chosen in the experiments, we can conclude that lower spindle speed when milling with radius end mills when milling with radius end mills and lower feed rates when using ball end mills will generate brittle material fractures. For a spindle speed of $4000 \mathrm{rev} / \mathrm{min}$ and a feed rate of $0.15 \mathrm{~mm} / \mathrm{rev}$ ductile-brittle transition fracture was obtained. in the case of hardened state during the hard machining of the AISI D2 steel chip takes a form of saw tooth with regular and irregular arranged lamellar structures on the free surface of the chip. All the heat sources produce maximum temperature at the chip-tool interface which substantially influences the chip formation mode and conduct to the apparition thermal crack on chip surfaces. White layer could be observed on some of the chips morphologies.

The experiments should be expended by considering a larger range of spindle speeds and end mills corner radius and other interest parameters like serrated frequency, shear band spacing, secondary serrated teeth spacing, etc.

The infrastructure used for this work was supported by the project "Integrated Center for research, development and innovation in Advanced Materials, Nanotechnologies, and Distributed Systems for fabrication and control", Contract No. 671/09.04.2015, Sectoral Operational Program for Increase of the Economic Competitiveness co-funded from the European Regional Development Fund.

\section{References}

1. I. Beşliu, L. Slătineanu, M. Coteață , D. Amarandei, Chip deformation in high speed face milling of the hard tool steel X210Cr12, AUO-FMTE, 1, 4 (2014)

2. J. Paulo Davim, Machining: Fundamentals and Recent Advances (EDP Springer Science \& Business Media, 2008)

3. S. Ben Salem, E. Bayraktar, M. Boujelbene, D. Katundi, Effect of cutting parameters on chip formation in orthogonal cutting, J. Achiev. Mater. Manuf. Eng., 50, 10( 2012)

4. X. M. Anthony, Analysis of cutting force and chip morphology during hard turning of Aisi D2 Steel, Journal of Engineering Science and Technology, 10, 3 (2015)

5. V. N. Gaitonde, S. R. Karnik, C. H. Alves Maciel, J. C. Campos Rubio, A. Mendes Abrão, Machinability Evaluation in Hard Milling of AISI D2 Steel, Mat. Res., 19(2), 9 (2016)

6. M. Takacs, B. Z.Farkas, Hard Cutting of AISI D2 Steel, Proceedings of ICMEM 2014, Prague, Czech Republic, (2014) 